\title{
Millennial Graduate Students' Use Of Technology And Problem-Based Learning To Enhance Higher-Level Cognition In Health Promotion Program Planning
}

June Matthews, Ph.D., RD, PHEc, Brescia University College, Canada Paula Dworatzek, Ph.D., RD, Brescia University College, Canada

\begin{abstract}
As 'Millennials', current graduate students are very familiar with technology. To engage these students in their learning, we incorporated higher-level cognitive processes and knowledge dimensions into our course objectives. We also asked students to use a novel on-line tool to complete their major assignment. Using problem-based learning and a population health approach, students collaboratively developed a multi-strategy university peer nutrition education program. Over a three-year period, each class used the Online Health Program Planner, a freely-available, web-based, interactive collection of health promotion planning tools. This practical application of course content enabled students to develop and practice core competencies in public health. Students' anonymous evaluations revealed that working with their colleagues on projects that would be used in a real-life setting "gave meaning to their work and motivated them to do their best". They believed that they learned more from this assignment than traditional class projects. They were surprised by the complexity involved in developing a comprehensive program, and learned to think critically about outcomes. Some students wanted more guidance throughout the project, reflecting challenges students often face during problembased learning; however, this also facilitated their learning at a higher level. These field experiences pushed students outside their comfort zones and promoted deeper learning than is possible through lectures alone. Other educators may find this type of project, in which experiential and problem-based learning were enhanced by comprehensive learning objectives and the use of a novel on-line tool, to be an appropriate transition from graduate school to professional practice.
\end{abstract}

Keywords: Millennial Graduate Students' Use Of Technology; Online Health Program Planner; Higher-Level Cognition In Health Promotion Program Planning

"Knowing is not enough; we must apply. Willing is not enough; we must do." - Goethe

\section{INTRODUCTION}

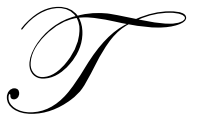

he Millennial students in our graduate classrooms today have lived most of their lives using the Internet and the World Wide Web. These digital learners are at ease with this technology and they have developed learning styles commensurate with it, yet traditional teaching methods have been slow to adapt (Tucker \& Courts, 2010). There are ways, however, in which we can enhance their learning experience.

Professors can start with learning objectives which include higher-level cognitive processes (e.g., analyze, evaluate, and create) as well as higher-level knowledge dimensions (e.g., conceptual, procedural, and metacognitive) 
(Anderson \& Krathwohl, 2001). Conceptual knowledge objectives would include an understanding of the theories that we expect students to learn and apply. Procedural knowledge objectives could include knowledge and application of skills and techniques, as well as the ability to determine "when to do what" (Anderson \& Krathwohl, p. 27). This is important for healthcare professionals as they must work within ethical guidelines and multiple legislative parameters. Metacognitive objectives include self-reflection as a necessary aspect of learning. This can be incorporated by having learners use their own relevant situational or cultural knowledge (e.g., being a student in a university setting) to address a problem or issue (Anderson \& Krathwohl).

Problem-based learning (PBL) is an instructional method whereby students work in collaborative groups to identify what they need to learn in order to solve a problem (Hmelo-Silver, 2004). It is an ideal pedagogical method to incorporate these higher-level cognitive and knowledge objectives. Millennial students can benefit from this approach as they work collaboratively, construct integrated knowledge, develop problem-solving skills, experience self-directed learning, and become intrinsically motivated. Faculty also benefit from this form of pedagogy as it keeps the teaching experience dynamic and enhances student engagement and motivation. The self-directed nature of PBL can be enhanced by projects that occur within a relevant real world setting. For Millennial graduate students, using on-line technology to address nutrition education goals within their community (i.e., the creation of a peer nutrition education program for university students) provides an invaluable and technologically relevant learning opportunity whereby they can develop higher-level workplace knowledge and skills such as problem-solving, critical analyses, creative solutions, communication, and evaluation.

\section{COURSE DESCRIPTION}

The graduate course in which these pedagogical approaches were combined was an advanced study of population health theory and practice, with emphasis on the planning and evaluation of programs to improve nutritional health. For each of the past three years, all students enrolled in the course have worked as a team to apply the course content to nutritional health promotion in their campus community. Guided by a population health approach, the students developed a comprehensive multi-strategy university peer nutrition education program, the goal of which is to improve the health of young adults as they transition to independent living. It is at this stage in the lifecycle that a lack of food skills and knowledge can become particularly problematic. This is an emerging issue in public health and one with which the graduate students can identify.

\section{Materials and Resources}

All three classes used an innovative on-line program called the Online Health Program Planner (OHHP) (The Health Communication Unit (TCHU) at Public Health Ontario and the National Collaborating Centre for Methods and Tools (NCCMT), 2009).The OHPP is a freely-available, web-based interactive collection of health promotion planning tools that is currently used in practice. Program Planning Steps guide users through six steps, the goal of which is the development of comprehensive, evidence-based program and the accompanying logic models. Also included in the collection is an Online Business Case Creator, an interactive tool designed to help public health practitioners make a compelling case for why to proceed (or not proceed) with a particular project. Three steps in this stage prompt users to assess the strengths and limitations of a project to identify risks and benefits; analyze how the risks can be minimized and the benefits maximized; and summarize their 'case' to advise various stakeholders and audiences. Project Management Tools include four steps to assess the context, scope, and assumptions of the project; available resources and budget; work plans; and stakeholder roles and expectations. By completing the interactive worksheets step-by-step, students learn how to create evidence-based, comprehensive plans. Moreover, similar to practitioners who can collaborate on large projects while being stationed at workplaces across wide geographical areas, the students were also able to work concurrently on the project on the OHPP website (TCHU \& NCCMT, 2009).

\section{Procedure}

The first group of students $(n=13)$ conducted a situational assessment and analysis of the barriers and facilitators to healthy eating and wellness in the university population. They utilized the OHHP to guide them through the steps required. They collectively identified the problem, determined relevant and appropriate sources of 
information, interviewed key stakeholders locally and at other universities, and prepared a detailed report on their findings. Next, they created a multi-strategy program plan and logic model to address the needs and assets identified in the situational assessment. Their detailed logic models included a variety of health promotion strategies, including information dissemination, skill building, social marketing, incentive programs, procurement policies, and a campus food advisory council - all of which required higher-order thinking and application.

Students enrolled the following year $(n=17)$ created evaluation tools to conduct a comprehensive scan of the campus food and nutrition environment (e.g., dining halls, vending machines, snack bars, etc.). They examined research that had been conducted in this area (Glanz, Sallis, Saelens, \& Frank, 2007; Saelens, Glanz, Sallis, \& Lawrence, 2007; Minaker, Raine, \& Cash, 2009), ultimately creating evaluation instruments that were relevant to their campus. Building on the work of the first two classes, the third group of students $(n=14)$ created a businesscase and implementation plan for the program, again using the online health program planner tools (TCHU \& NCCMT)

Each year, the students worked as a team, self-organizing into sub-groups, with two students taking on leadership roles as project managers. Each week, one hour of class was reserved for in-class meetings and structured opportunities for reflection, enabling the students to connect their field experience with course content. These practical applications of course content enabled the students to develop and practice core competencies necessary for the practice of public health, including assessment and analysis, program planning and evaluation, collaboration, communication, project management, and leadership (Public Health Agency of Canada, 2008). This resulted in a higher-level learning process through which students drew upon the knowledge and skills they gained to create a deeper, more complex understanding and application of knowledge. Furthermore, the students tackled a relevant, real-world problem by analyzing, synthesizing, making judgements, and applying theories, all of which are valued components of higher-level learning as assessed in the National Survey of Student Engagement (Indiana University Centre for Postsecondary Research, 2011).

\section{Evaluation}

Evaluation of this multi-year project occurred informally during weekly in-class meetings conducted by the students; the instructors provided feedback only when necessary. Everyone discussed issues which arose and reflected on ways to resolve them. Several stakeholders, including representatives from campus food services and public health, attended the students' end-of-semester presentations, where they presented their ideas, witnessed reactions to their recommendations, and recognized that their work is part of a long-term effort that will evolve over time (Henry, 2011). Stakeholders provided feedback on both the process and the product.

More formally, students' anonymous end-of-course evaluations revealed that working with their colleagues on projects that were going to be used in a real-life setting "gave meaning to their work and motivated them to do their best". They felt that they learned more from this assignment than traditional class projects and appreciated the opportunity to engage in higher-order thinking by bringing together a variety of ideas to create a peer nutrition education program for university students. They were surprised by the complexity involved in developing a comprehensive program or evaluation plan, and learned to think critically about program outcomes and the multiple ways in which to achieve them. Their greatest challenges were logistics, communication, and ensuring quality work was submitted on time. Some students said they didn't know "what was expected of them" or if they were "on the right track". They wanted more guidance throughout the project, and clearer roles for project managers. These comments reflect the challenges students face when they encounter problem-based learning, but it is precisely this lack of guidance that facilitates their learning at a higher cognitive level. In the end, the students were proud that they were able to "overcome all the challenges" to "effectively pull it all off". They felt empowered that their work might "actually create change on campus" and "benefit the entire university community", reflecting satisfaction with the relevant experiential component. One wrote, "I am amazed at what ... we as a group have produced". Another recommended that we "keep the project ... in the future as it was incredibly worthwhile". Unsolicited feedback came via email when two former students commented that their learning curve was "lessened dramatically" when, in their new positions, they were asked to use the OHHP to develop nutrition education programs. 


\section{CONCLUSIONS AND IMPLICATIONS FOR PRACTICE}

We took all feedback into consideration, and have continued to include these problem-based experiential learning projects in our graduate course, as students learned more by 'doing' than simply 'knowing'. Similar to other graduate courses, where service-learning components have promoted higher-level learning among future professionals (Kopera-Frye \& Hilton, 2008), our students were also held accountable for producing a realistic plan that could be implemented within their university community. Furthermore, the production of a program or evaluation plan required the coordination of the four types of knowledge - factual, conceptual, procedural, and metacognitive (Krathwohl, 2002) - all of which are necessary for the intellectual development of students in a professional graduate program. Additionally, peer working groups offered a forum where students could constructively review and critique each other's writing, learn to navigate relationships in a mature group context, share knowledge, and provide encouragement (Remmes Martin \& Ko, 2011). These field experiences also pushed students outside their comfort zones and promoted deeper learning than is possible through lectures alone. Other educators may find this type of project, in which experiential and problem-based learning were enhanced by comprehensive learning objectives and the use of a novel on-line tool, to be an appropriate transition from graduate school to professional practice.

\section{AUTHOR INFORMATION}

June Matthews is an Associate Professor in Food and Nutritional Sciences at Brescia University College, Western University, London, Canada. As a Registered Dietitian and a Professional Home Economist, Dr. Matthews' research interests are in the areas of peer education, food systems and food skill development, community gardening, and the relationships among policies of agriculture, food, and nutrition. Dr. Matthews often incorporates unique pedagogical approaches into her teaching. She received the 2008 Brescia University College Award for Excellence in Teaching and has been nominated for the 2011 Scholarships Canada 'Dream Maker Award' for making a positive difference in students' education. E-mail: jmatth22@uwo.ca. Corresponding author.

Paula Dworatzek is an Associate Professor in Food and Nutritional Sciences at Brescia University College, Western University, London, Canada. Dr. Dworatzek has been involved in the development of Clinical Practice Guidelines for the Prevention and Management of Diabetes and Recommendations for Nutrition Best Practice in the Management of Gestational Diabetes in Canada. Her research interests include the prevention of obesity and chronic disease, nutrition education program planning and evaluation, and peer education. As a Registered Dietitian with practical experience in community settings, Dr. Dworatzek also provides students with practice-based activities and assignments to develop their competencies as future nutrition educators. E-mail: pdworatz@uwo.ca. Corresponding author.

\section{REFERENCES}

1. Anderson, L. W., \& Krathwohl, D. R. (2001). A taxonomy for learning, teaching, and assessing: a revision of Bloom's Taxonomy of Educational Objectives. New York, NY: Longman.

2. Glanz, K., Sallis, J. F., Saelens, B. E., \& Frank, L. D. (2007). Nutrition Environment Measures Survey in Stores (NEMS-S): development and evaluation. American Journal of Preventive Medicine, 32, 284-91. doi: 10.1016/j.amepre.2006.12.019

3. Henry MC. (2011). Reflection matters: Connecting theory to practice in service learning courses. Kappa Omicron Nu Forum, 15(2). Retrieved from http://www.kon.org/archives/forum/15-2/henry.html

4. Hmelo-Silver, C. E. (2004). Problem-based learning: what and how do students learn? Educational Psychology Review, 16, 235-266.

5. Indiana University Centre for Postsecondary Research. (2011). National Survey of Student Engagement (NSSE). Retrieved from http://nsse.iub.edu/

6. Kopera-Frye K, \& Hilton J. (2008). "Learning by doing" in a graduate course in Human Development and Family Studies: service learning utilizing an evaluation project. Collected Essays on Teaching and Learning, 1, 93-98. Retrieved from http://apps.medialab.uwindsor.ca/ctl/CELT/celtvol1.html

7. Krathwohl, D. (2002). A revision of Bloom's taxonomy: an overview. Theory into practice, 41,212-218. 
8. Minaker, L. M., Raine, K. D., \& Cash, S. B. (2009). Measuring the food service environment: development and implementation of assessment tools. Canadian Journal of Public Health, 100, 421-25.

9. Public Health Agency of Canada. (2008). Core competencies in Public Health: Release 1.0. Ottawa, Canada. Public Health Agency of Canada. ISBN: 978-0-662-05421-4.

10. Remmes Martin, K., \& Ko, L. K. (2011). Thoughts on being productive during a graduate program: The process and benefits of a peer working group. Health Promotion Practice, 12, 12-17. doi: $10.1177 / 1524839910383687$

11. Saelens, B. E., Glanz, K., Sallis, J. F., \& Lawrence, F. (2007). Nutrition Environment Measures Study in Restaurants (NEMS-R). American Journal of Preventive Medicine, 32, 273-281. doi: 10.1016/j.amepre.2006.12.022

12. The Health Communication Unit (TCHU) at Public Health Ontario and the National Collaborating Centre for Methods and Tools (NCCMT). (2009). Online Health Program Planner. Retrieved from http://www.thcu.ca/ohpp/

13. Tucker, J., \& Courts, B. (2010). Utilizing the Internet to facilitate classroom learning. Journal of College Teaching and Learning, 7, 37-42. 
NOTES 